\section{Рада Ивековиќ}

\section{ПОЛОТ НАНАЦИЈАТА*}

Rada Ivekovic

\section{LE SEXE DE LA NATION*}

$\mathrm{K}$ онструкцијата на секој идентитет, како мисловен така и религиозен, културолошки, лингвистички или кој било друг, се реализира со посредство на една претходна дефиниција на социјалните односи на половите. Истото тоа важи и за т.н. етнички и/или национален идентитет.

Имајќи ги предвид сите разлики, речиси во сите општества пустоши една, помалку или повеќе, апсолутна сегрегација на половите. Тоа е она што некои го нарекуваат род. Ваквото раздвојување е секако многу поприсутно во Т.н. традиционални општества, но сѐ уште може да се воочи, на извесен начин и на различни нивоа, дури и во модерните општества. Значи полот е можеби токму тоа: еден првобитен расцеп на/во самата мисла, едно нејзино раздвојување пред таа самата да се осознае. Се работи за едно подвојување на свеста на кое што во исто време му кореспондира едно одвојување на природата од културата. Тоа бара една редовна реконструкција (секогаш во, и почнувајќи од, половите разлики) бидејќи таквата двојба е секогаш мошне кревка. Нашата природа, всушност, е секогаш веќе култура, и самиот „пол" е далеку од тоа да се претставува во една „чиста" состојба на природата. Оваа постојано реконфигурирана поделба е исто така и обид да се опфати човекот, тој кој што секогаш има тенденција да се прелее кон она што би сакал да го смета за анималност, за другост. Раздвојувањето на половите a construction de toute identité, qu'elle soit pensée comme religieuse, culturelle, linguistique, ou autre se fait au moyen d'une définition préalable des rapports sociaux des sexes. Il en va de même de l'identité dite ethnique et/ou nationale.

II sévit dans toutes les sociétés, toute proportion gardée, une plus ou moins absolue ségrégation des sexes. C'est aussi ce que certains appellent le genre. Cette séparation est certes beaucoup plus présente dans les sociétés dites traditionnelles, mais elle reste encore perceptible, à certains égards et à divers degrés, même dans les sociétés modernes. Or, le sexe n'est peut-être que cela: une scission première de/dans la pensée elle-même, un partage avant qu'elle ne (se) réfléchisse. II s'agit d'un partage de la raison, auquel correspond en même temps le partage entre la nature et la culture. Ce dernier est régulièrement reconstruit (toujours en, et à partir de, la différence des sexes) car toujours fragile. Notre nature, en effet, est toujours déjà culture, et le "sexe" lui même est loin de se présenter à l'état "pur" de nature.Cette division constamment reconfigurée est aussi une tentative pour contenir l'humain, lui qui a toujours tendance à déborder vers ce qu'il aimerait pouvoir considérer comme animal, comme autre. La séparation des sexes est la vaine tentative toujours re-tentée de recentrer l'anthropocentrisme, dont la forme prévalente n'a été qu'androcentrisme.' Le genre (le sexe social) est "un modèle 
е напразен обид, секогаш наново практикуван, да се рецентрализира антропоцентризмот, чија предоминантна форма бил самиот андроцентризам. ${ }^{1}$ Родот (социјалниот пол) е „еден модел на социјални односи, конструиран и оперативен во социјалната практика". 2

„Создавајќи го тој имагинарен елемент каков што е дполоте", пишува Мишел Фуко, „половиот диспозитив разбуди еден од оние најосновни внатрешни принципи на функционирање. (...) Нужно е да се ослободиме токму од инстанцата на полот доколку сакаме, преку едно тактичко навраќање на различните механизми на половоста, да ја истакнеме, наспроти достигањата на моќта, вредноста на телото, задоволството, знаењето, во нивната разновидност и нивната можност да се спротистават. Наспроти диспозитивот на половоста, потпорна точка на противнападот не треба да биде полот-желба, туку телото и задоволствата". ${ }^{3}$ Бидејќ половоста отсега станува еден вид полиција која функционира во најразлични домени.

Риту Менон насловува една од своите статии „Дали жените имаат татковина?". ${ }^{4}$ Во неа таа покажува како нацијата се конструира со посредство на една веќе востановена хиерархија на половите и без жената да биде земена предвид. Ваквата хиерархија е еден од главните услови, а во исто време и механизам за интеграција на нацијата. Но ние мораме да го разгледаме „уредувањето на односите меѓу половите“ и во други формации за да можеме да го разбереме и на ниво на нацијата.

„Било да е тоа во Израел, Босна или во Северна Ирска, жените беа во голема мера исклучени од плановите за решавање на конфликтите како и од процесите на конституирање на нацијата-Држава", пишува Наџе Ал-Али. "Иронично, но нивната маргинализација во однос на поофицијалните и поформални канали на политиката можеше да ја зголеми способноста да се мисли и да се делува надвор од идеологијата и од текот на акцијата предвидена од страна на доминантните елити, воглавно од машка природа. Наместо да се потчинат токму на улогите кои им се припишани како биолошки и културолошки создателки на de rapport sociaux, construit et opératoire dans la pratique sociale". ${ }^{2}$

"En créant cet élément imaginaire qu'est 'le sexe'," écrit Michel Foucault, "le dispositif de sexualité a suscité un de ces principes internes de fonctionnement les plus essentiels. (...) C'est de l'instance du sexe qu'il faut s'affranchir si, par un retournement tactique des divers mécanismes de la sexualité, on veut faire valoir contre les prises du pouvoir, les corps, les plaisirs, les savoirs, dans leur multiplicité et leur possibilité de résistance. Contre le dispositif de sexualité, le point d'appui de la contre-attaque ne doit pas être le sexe-désir, mais les corps et les plaisirs." sorte de police qui fonctionne dans les domaines les plus divers.

Ritu Menon intitule l'un de ses articles "Les fernmes ontelles un pays?"4 Elle y montre comment la nation se construit au moyen de la hiérarchie des sexes maintenue et sans considération pour les femmes. Cette hiérarchie est l'une des principales conditions ainsi que le mécanisme d'intégration pour la nation. Mais nous devons observer les "régimes de rapports des sexes" dans d'autres formations pour le comprendre aussi au niveau de la nation.

"Que ce soit en en Israel, en Bosnie et en Irlande du Nord, les femmes ont été largement exclues des projets de résolution des conflits ainsi que des processus de construction de la nation-Etat", écrit Nadje Al-Ali. "Ironiquement, leur marginalisation par rapport aux canaux plus officiels et formeis de la politique pourrait avoir augmenté l'abileté à penser et à agir en dehors de l'idéologie et du courant de l'action prévu par des élites dominantes, principalement masculines. Au lieu de se soumettre exactement aux rôles qui leurs sont assignés, en tant que reproductrices biologiques et culturelles de la nation, les femmes (...) résistent activement non seulement aux rôles 
нацијата, жените (...) активно се спротиставуваат не само на традиционалните улоги на родот но исто така и на преовладувачките концепции за дзаедницатае и днацијатае."

Нацијата, во сопствената конституција, експлицитно се потпира врз моделот на семејството. ${ }^{6}$ Сѐ уште е во улотреба начинот на определување на статусот и репутацијата на една нација, понекогаш и на една држава, преку степенот на нејзините машки надлежности. Таткото на нацијата би бил исто што и таткото на семејството, на претпријатието ${ }^{7}$ итн. што во секој случај го делолитизира односот меѓ половите. Тоа сака да каже дека разликата меѓ половите ги информира, поминува низ и ги поврзува меѓу себе институциите на различни нивоа, од најниско до највисоко. Секоја социјална формација е полова на еден или на друг начин. Според Мишел Фуко, самиот пол, којшто во голема мера служи за дисциплинирање и регулирање на телата и популациите, е еден исклучително силен прелом на моќта.Ние имаме обичај да ја разгледуваме проблематиката на разликата меѓу половите (или родовите) особено на микро-ниво, онаму каде што е лесно воочлива поради едно лично и директно искуство: сексуално будење, семејство, приватен живот, училиште, полова поделба на работата дома ловеќе отколку на кое било друго место, редовното насилство кон изолираните жени итн., сето ова сведочи за различните видови „режим на односите меѓу половите“, односно „родов режим“. Од феминистите, социолозите, статистичарите, можеме да научиме дека диференцирањето на половите се појавува подеднакво и на други нивоа (на средно ниво): заедницата, општеството, културата и самата држава на различни начини го артикулираат социјалниот и политичкиот однос меѓу половите. Тука веќе, перцепцијата е помалку директна и зависи исто така во голема мера од сензибилитетот на поединецот. Науките со кои располагаме се создадени без да го земат предвид режимот на половите. Перцепцијата на односот меѓ половите е во секој случај (исто така) културолошки условена и не е неутрална. На едно уште лоапстрактно ниво, на ниво на државата, на односите меѓу државите, значи во меѓународните работи, а денес и во процесот на мондијализација, уште е потешко да се согледа половата/ traditionnels de genre mais également aux conceptions prévalentes de la 'communauté' et de la 'nation'."'5

La nation, dans sa constitution, prend explicitement modèle sur la famille. ${ }^{6}$ Et il est encore d'usage de mesurer le statut et la réputation d'une nation, parfois d'un Etat, par le degré de ses attributions masculines. Le père-de-la-nation serait comme le père de famille, de l'entreprise ${ }^{7}$ etc., ce qui dépolitise en tout cas le rapport des sexes. Cela veut dire que la différence des sexes informe, traverse et lie entre elles des institutions de niveau différent, du plus bas, au plus haut. Toute formation sociale est sexuée d'une manière ou d'une autre. Pour Michel Foucault, le sexe lui-même, qui sert largement à discipliner et à réglementer les corps et les populations, est un pli particulièrement puissant du pouvoir. Nous avons l'habitude de discerner la problématique de la différence des sexes (ou des genres) surtout au microniveau, là où elle saute aux yeux du fait d'une expérience directe et personnelle: réveil sexuel, famille, vie privée, école, division sexuelle du travail à domicile plus qu'ailleurs, violence ponctuelle contre des femmes isolées etc., tout cela témoigne de "régimes de rapports des sexes" ou de "régimes des genres" différents. Par les féministes, les sociologues, les statistiques, nous apprenons que la différence des sexes apparaît également à d'autres niveaux (au niveau moyen) : la communauté, la société, la cuiture, et l'Etat même articulent de manières différentes le rapport social et politique des sexes. Là déjà, la perception en est moins directe, et elle dépendra aussi en grande partie de la sensibilité de chacun. Les sciences dont nous disposons sont construites sans prendre en compte le régime des sexes. La perception du rapport des sexes est en tous cas (aussi) culturellement conditionnée, et n'est pas neutre. A un niveau encore plus abstrait, au niveau de l'Etat, des rapports entre les Etats, donc des affaires internationales, et, aujourd'hui, de la mondialisation, il est encore plus difficile de saisir l'articulation sexuelle/des genres. Il est difficile de dire, sauf de manière très générale, en quoi tous ces rapports sont aussi conditionnés par la hiérarchie des sexes et d'en calculer la mesure et les effets. Certes, il y a à ce sujet aujourd'hui des bibliothèques entières, et nous sommes très loin de les avoir toutes parcourues. Ce qui nous intéresse cependant, c'est aussi un problème méthodolo- 
родовата артикулација. Тешко е да се каже, освен можеби на еден општ начин, во што целокупните односи се условени од хиерархијата на половите, во колкава мера и со какви ефекти. Секако, по однос на ова прашање денес постојат цели библиотеки, и ние ни од далеку не можеме сите да ги опфатиме. Она што секако не интересира е исто така и проблемот на методологијата. Покрај несомнената патријархална пристрасност која редовно и насилно го поматува секое размислување по односниот предмет (нешто што нужно мора да се надмине), исто толку сигурно е дека кога ке наидеме на пречки при концептуализирањето на извесна проблематика, токму теоретскиот апарат, терминологијата со кои располагаме не се адекватни за да ја изразат. Ние го воведуваме во нашата работа концептот на „режим на социјалните односи меѓу половите“ што го позајмуваме од Силвија Валби, Gender, nations and states in a global era. ${ }^{8}$ Постојат различни видови на режими од полова природа, на сите нивоа на опсервација, и можат да се разликуваат едни од други дури и во рамките на едно исто општество: семеен полов режим, национален полов режим, полов режим во претпријатијата, полов режим во државата, полов режим во регионалните интеграции и во односите меѓу државите, полов режим во глобализацијата, во Обединетите нации итн. На пример, семејниот режим може да биде поинаков од половиот режим во школството и медицината итн., режимот на заедницата ( на идентитетот или „етничкиот“ режим) е многу поразличен од социјалниот (граѓански) режим на половите итн., истовремено разликувајќи се од режимот во културата или од "половиот" режим во државата, додека овој последниот може во значителна мера да се разликува од еден мегународен, помалку или повеќе распространет, режим на уредување на односите меѓу половите. За самите жени, помеѓу традиционалните општества и едно модерно општество, постои многу голема разлика помеѓ домашниот и семејниот режим кој ги држи затворени дома, и „јавен“ полов режим каде што тие излегуваат во општеството поради бројни економски и политички активности. Воведувањето на концептот на gender regime од страна на Силвија Валби е исклучително важно и ќе дозволи согледување и искажување на феномените кои досега иे бегаа на gique. Au delà de l'indubitable partialité patriarcale qui forcément obnubile généralement toute réflexion à ce sujet (et qu'il faut donc dépasser), il est sûr que si nous rencontrons quelques embûches à conceptualiser une problématique, c'est que l'appareil théorique, la terminologie, dont nous disposons ne sont pas adéquats pour l'exprimer. Nous introduirons dans notre travail le concept de "régime des rapports sociaux de sexe" que nous empruntons à Sylvia Walby, "Gender, nations and states in a global era". ${ }^{8}$ II y a toutes sortes de régime des sexes, et a tous les niveaux d'observation, et ils peuvent être distincts les uns des autres même au sein d'une seule société: le régime familial des sexes, le régime national des sexes, le régime des sexes en entreprise, le régime des sexes de l'Etat, le régime des sexes dans les intégrations régionales ou les relations entre Etats, le régime sexuel de la globalisation, celui des Nations Unies etc. Par exemple, le régime familal peut être différent du régime scolaire ou du régime médical des sexes etc., et le régime communautaire (identitaire et "ethnique") est très différent du régime social (civique) des sexes etc., tout en se différenciant du régime culturel ou du régime "sexuel" de l'Etat alors que ce dernier lui-même peut diverger de manière importante d'un régime international, plus ou moins étendu, des sexes. Pour les femmes elles-mème, entre une société traditionnelle et une société moderne, s'installe la très grande différence entre un régime domestic et familial qui les retient à la maison, et un régime des sexes "public", ou elles sortent dans la société pour de nombreuses activités économiques et politiques. L'introduction du concept de gender regime par Sylvia Walby est extrêmement important et permettra de saisir et d'exprimer des phénomènes qui jusque-là se dérobaient à l'analyse, à des échelles où, en générale, il était difficile d'appliquer la catégorie de sexe/genre. 
анализата, на нивоа каде што, воглавно, беше тешко да се употреби категоријата на полот/родот.

Концептите на „нацијата“, „заедницата“, „татковината“, „потеклото“, „културата“" се во голема мера полово конотирани. Идејата што ја имаме за сопственото тело, за сексуалноста, за социјалниот однос мегу половите и за половиот морален поредок, како и за јазикот преку кој нив ги изразуваме, претставуваат референца за ваквите концепти. Тоа е всушност случајот со сите хиерархии: сите се полово детерминирани. Било да се работи за класи или касти, старосни групи, „систем на симболи“, административна дисциплина во рамките на институциите и државата, доминантни идеологии, полов режим, обичен расизам, светски поредок итн. сите тие се инсталираат почнувајќ од една редефиниција на улогата на двата пола и се чини дека ова е фундаментално и прелиминарно на нивната сопствена конструкција. ${ }^{10}$ Претставувањето на една нација или на еден национален проект (еден патриотизам), со оглед на сите разлики, секогаш содржи елаборации на помалку или повеќе востановени слики за секој од половите. Нормативните дескрипции се менуваат мошне тешко, под притисок на моментите на големи кризи и на општа реконфигурација.Овој клучен фактор во конституирањето на нацијата е потполно занемарен кај повеќето автори кои ја проучуваат динамиката на нацијата и национализмите, со исклучок на Етјен Балибар и повеќе индиски истражувачи, како што се Р. Самадар," Парта Шатерџи, Амартја Сен и други.

Но, пред ваквото полово определување на концептите, веќе постои една двојба на свеста во зависност од дистрибуцијата и распределбата на половите „вредности“. Тоа кореспондира на дистинкцијата меѓ разумот и светот, субјектот и објектот, машкото и женското, итн. Без да бидат сосема еквивалентни, овие дихотомии се секогаш корелативни и ја содржат „разликувачката валентност на половите“ (Ф. Еритје).

Постои ли врска помеѓу патриотизмот како чувство (еуфемизам за „национализам") и разликувањето на половите? На еден очигледно уште поанегдотичен начин, постои тесна поврзаност помеѓу патриотизмот ${ }^{12}$ и љу-
Les concepts de "nation", " communauté", "patrie", "origine", "culture"g sont hautement connotés sexuellement. Ils sont liés à des images de (corps de) femme. L'idée que l'on se fait de son propre corps, de la sexualité, du rapport social des sexes et de l'ordre moral sexuel, ainsi que le langage par lequel on en parle, font référence à ces concepts. C'est d'ailleurs le cas de toutes les hiérarchies: toutes sont sexuées. Que ce soient les classes ou les castes, les groupes d'âge, le "système symbolique", la discipline administrative au sein des institutions et de l'Etat, les idéologies dominantes, le régime des sexes, le racisme ordinaire, l'ordre mondial etc., ils s'installent tous en commençant par redéfinir le rôle des deux sexes et ceci semble être fondamental et préliminaire à leur construction. ${ }^{10}$ Une représentation de la nation ou un projet national (un patriotisme), toute proportion gardée, ont toujours des élaborations d'images plus ou moins arrêtées de chacun des sexes. Ces descriptions normatives ne changent que très difficilement, poussées par les grands moments de crise et de reconfiguration générale. Ce facteur crucial de la constitution de la nation est complètement négligé chez la plupart des auteurs qui étudient la dynamique de la nation et des nationalismes, à l'exception d'Etienne Balibar et plusieurs chercheurs indiens, tels que R. Samaddar," Partha Chatterjee, Amartya Sen et autres.

Mais en amont de la sexuation des concepts, il y a déjà le partage de la raison selon la distribution ou la répartition des "valeurs" sexuelles. II correspond à la distinction entre raison et monde, sujet et objet, masculin et féminin etc. Sans être complètement équivalentes, ces dichotomies sont toujours correlatives et comportent la "valence différentielle des sexes" (F. Héritiẹr)

Y-a-til un rapport entre le patriotisme en tant que sentiment (euphémisme pour "nationalisme") et la différence des sexes? De manière apparemment plus anecdotique, il existe une connexion étroite entre le patriotisme ${ }^{12}$ et l'amour. Dans 
бовта. Во извесни стереотипни и скаменети форми на литературата, една исклучителна форма на аскетизам, сублимација и патриотска преданост се состои во тоа да се замени, кај еден национален херој, кај еден човек од политиката, љубовта спрема жената со љубовта слрема татковината. Обратното важи за жените: клишето бара мажот да биде вистинска татковина или вистинска религија на жената, нејзиниот маж да биде нејзиниот единствен Бог, ${ }^{13}$ според индиската поговорка. Во исто време, при таквиот идеал за насилниот "мажествен" маж, јуришот кон непријателот ќе биде проследен со напад на женственоста (внатрешна) ${ }^{14}$, на слабоста како таква. Во една мачо-национална и етатистичка верзија, овој маж го „сака“ својот народ, својата татковина, својата војска, своето знаме, својата култура на која иे нема рамна (накратко, својата единствена Култура), својата пушка. На последнава й посветува песни како на своја сакана, тој спие со своето оружје. ${ }^{15}$ Неговиот говор станува декламативен. Објектот на неговата љубов е обезживотен, дури и кога се работи за форма на човечко суштество. Тоа е всушност секуларизација на религиозниот модел која започнува со Романтизмот, или уште поскоро од Просветителството наваму. ${ }^{16}$ Заедницата така го обезличува свештеничкиот поредок, но ги има сите шанси да се уназади и самата себе си.

„Жените се наоѓаат во една релација на угнетеност во однос на мажите, општеството и државата." ${ }^{17}$ И, треба ли да се додаде, посебно во однос на заедницата и на нејзината специфична форма, нацијата. ${ }^{18}$ Различните улоги што им се припишуваат на мажите и жените лреку една историски полова социјализација се диференцираат посебно по однос на моќта, која пак, ја определува нацијата како една хиерахиска, вертикална и исклучива конструкција. Сепак, таа почива подеднакво и врз други форми на моќ и хиерархија.

Наспроти ваквата историски добро документирана очигледност, во она што следи ќе се интересираме поскоро за родовата детерминираност ("gendering") на извесни институции и на размислувањата во врска со нив. Филозофијата или хуманистичките науки ке бидат исчитувани на мес- certains cas stéréotypés et figés en littérature, une forme particulière d'ascetisme, de sublimation et de dévotion patriotique consiste à remplacer, chez un héro national, chez un homme politique, l'amour pour une femme par l'amour pour la patrie. L'inverse vaut pour les femmes: le cliché veut que l'homme soit la véritable patrie ou la vraie religion de la femme, que son mari soit son seul dieu ${ }^{13}$ selon le dicton indien. En même temps, dans l'idéal de l'homme "viril" violent, l'assaut à l'ennemi sera corroboré par l'attaque à la féminité (intérieure), ${ }^{14}$ à la faiblesse en tant que telle. Dans la version macho-nationale et étatique, cet homme "aime" son peuple, sa patrie, son armée, son drapeau, sa culture sans égale (la Culture tout court, la seule), son fusil. $\mathrm{A}$ ce dernier il dédie des poèmes comme à sa bien-aimée, il dort avec son arme. ${ }^{15}$ Son discours devient déclamation. L'objet de son amour est dévitalisé, même quand il s'agit pour la forme d'un être humain. C'est la sécularisation du modèle religieux, qui commence depuis le Romantisme, et plus précisément à partir des Lumières. ${ }^{16}$ La communauté défait ainsi l'ordre ecclesiastique, mais a toutes les chances de se replier sur ellemême.

"Les femmes se trouvent dans une relation d'oppression par rapport aux hommes, à la société et à l'Etat."17 Et, faut-il ajouter, par rapport surtout à la communauté et à sa forme spécifique, la nation. ${ }^{18}$ Les rôles différents assignés aux hommes et aux femmes par une socialisation historiquement sexuée sont différenciés surtout par rapport au pouvoir qui, lui, détermine la nation en tant que construction hiérarchique, verticale et exclusive. Cependant celle-ci repose également sur d'autres formes de pouvoir et de hiérarchie.

Au delà de cette évidence aujourd'hui historiquement bien documentée, dans ce qui suit on s'intéressera plutôt à la sexuation ("gendering") de certaines institutions et de la réflexion à leur propos. La philosophie ou les sciences humaines seront lues sur les lieux de leur occultation consitutive, pour elles-mêmes, 
тата на нивната конститутивна притемнетост, самите за себе, во хиерархијата на половите (е не во разликувањето на половите). Тешка лектира, бидејќ таквиот заборав долго му беше потребен на знаењето, уште од самиот почеток на неговото постоење. Така, една иста заслепеност е во основата на нацијата и на нејзиното проучување, бидејќи ги води една иста рационалност. Токму поради тоа процесот на повторно присеќавање претставува тешка работа. Фуко констатира ист тип на притајување во правото кое ги прикрива механизмите на моќта и на неговото сопствено потекло, па може да фаворизира дури и погрешна теорија за да си обезбеди функционирање. Според него, тоа е случај кога биополитиката која го напуштила божественото право, сѐ уште се повикува на теоријата на сувереноста (која, пак, е ставена во погон преку една „полова полиција“).

Разликата меѓ половите е една од најстарите интра-родови разлики што ги познаваме, не во биолошка туку во една политичка смисла. Од еден политички агол, разликата е спор ${ }^{19}$ и се оддалечува од биологијата, истовремено претендирајќи да се оправда со неа. Но ниту едното, ниту другото (ни биолошкото, ни политичкото) не можат да бидат дефинирани без извесни резерви. Како природна, разликата е помала од онаа што прави да се разликуваме од другите видови, иако нејзината перцелција е оптоварена со симболични и имагинарни вредности. Културолошки и низ епохите, разликата можела да биде кодирана како поважна, кога се сакало да се наметне верување дека жената е поблиска до анималните женки отколку до мажот. Тоа нѐ доведува до согледувањето на разликата меѓ половите како најстар лолитички спор што постои, оној којшто ја оцртува првата граница на другоста. Таа е во средиштето на односите на моќта. Традиционално гледано, пак, сѐ до филозофиите каде што тоа може и да зачуди, разликата меѓ половите е согледувана исклучиво како природна. ${ }^{20}$ Слорот меѓу половите воглавно не е земен предвид. „Неусогласеноста на барањата на жените во однос на придобивките на мажите не дозволуваше ваквото исчекување да се разбере низ термините на политиката" би можеле да ја парафразираме Мишел Рио-Сарси. ${ }^{21}$ Ваквото разидување е од почетокот запишано во јазикот како неутрализирано, деполитизирано, de la hiérarchie des sexes (et non de la différence des sexes). Lecture difficile, car cet oubli a longtemps été nécessaire au savoir comme celui-ci a été construit. Ainsi, une même cécité est à la base de la nation et de l'étude de celle-ci, car une même rationalité les gère. C'est pour cela que toute remémoration est un dur travail. Foucault constate le même type d'escamotage dans le droit, qui déguise les mécanismes du pouvoir et de sa propre origine, et peut même avancer des théorie éronnée pour s'assurer le fonctionnement. C'est le cas, pour lui, lorsque la biopolitique, qui a abandonné le droit divin, fait encore appel à la théorie de la souveraireté (alors qu'elle est mise en acte par une "police sexuelle").

Celie des sexes est la différence intra-générique la plus ancienne que nous connaissions, non dans un sens biologique mais dans un sens politique. Sous l'angle politique, la différence est différend ${ }^{19}$ et s'écarte du biologique, tout en prétendant se justifier par lui. Mais ni l'un ni l'autre (le biologique, le politique) ne peuvent être définis sans équivoque. En tant que naturelle, la différence est moindre que celle qui nous distingue des autres espèces, bienque la perception en soit chargée de valeurs symboliques et imaginaires. Culturellement et par époques, elle a pu être côdée comme plus importante, quand on a voulu faire croire que la femme était plus proche des femelles animales que de l'homme. Cela nous amène à voir la différence des sexes comme le plus ancien différend politique qui soit, celui qui désigne la première frontière de l'altérité. Celle-ci est au coeur du rapport au pouvoir. Traditionnellement au contraire, jusque dans les philosophies où cela peut étonner, la différence des sexes est vue comme seulement naturelle. ${ }^{20}$ Le différend des sexes n'est généralement pas pris en compte. "Le décalage des revendication des femmes par rapport aux acquis des hommes ne permettait pas de comprendre cette attente en termes politiques", pourrait-on paraphraser Michèle Riot-Sarcey. ${ }^{21}$ Cet écart est d'emblée inscrit dans le langage comme neutralisé, dépolitisé, sujet à un jugement tacite préalable qui présuppose l'adhésion de tous. Le silence à son propos est la condition de son fonctionnement en tant qu'agencement, producteur d'ordre 
подложено на една претходна премолчена проценка која претлоставува вклученост на секој поединец. Молчењето по однос на тоа разидување е услов за негово функционирање во смисла на поредок, продуцирање на ред и смисла. Она што овде е окултно, тоа е "уделот на оние без удел".22 Овој спор е всушност тенденција да се избегне проучувањето. Тешко е да се разграничат разликата и спорот мегу половите како лредмет на опсервација. Со самото тоа што се запишани во јазикот кој исто така е полово олределен, се чини дека тие отсекогаш биле таму. Уште пред човекот, уште пред јазикот кој веќе ги предвидува. Тешкотијата доаѓa оттаму што не може да се идентификува ниту една определувачка и одлучувачка карактеристика на полот или на родот, иако и двете претендираат кон есенцијалност. Овој спор, согледан како фундаментален - бидејќи е услов за живот - успева да го „о-полови“_нашиот универзум во сите негови детали благодарение на неговиот специфичен статус кој е многу повеќ од една природна разлика. Тоа е токму затоа што тој е политички. Спорот меѓу половите сѐ уште останува лреокупација на специјалистите или на активистите. Многу споро, преку аргументите на феминистичката критика, тој го проби својот пат во хуманистичките науки почнувајќ од антропологијата, станувајќи предмет на проучување исто колку и фактор на промени во постапките. Според Пјер Бурдіе, „специфичната сила на машката социо-единка догѓ од акумулацијата и кондензацијата на две операции: таа легитимира една релација на доминација впишувајки ја во една билошка природа која и самата е конструкција на едно натурализирано општество." ${ }^{\text {"з }}$

Најчесто, спорот меѓу половите е асимилиран во разликата меѓу половите, последнава од фантазамгорична природа, при што спорот е политички, а разликата, и покрај убедувањата дека е природна, сепак е конструирана. Помеѓу двата термини има еден мобилен, нестабилен однос, и една тензија, па дури и поврзаност, без таа да биде предетерминирана, дефинитивна и идентификативна. Политиката е конечно средиште на потенцијална власт-моќ. ${ }^{24}$ Токму спорот меѓ половите е интересен за филозофијата бидејќ е од политичка природа, што не е случај со разликата. Слротивно на она што стекнатата идеја за разли- et de sens. Ce qui y est occulté, c'est la "part des sans part".22 Ce différend a en effet tendance à se soustraire à l'examination. II est difficile de cerner la différence et le différend des sexes comme objet d'observation. Du fait qu'ils sont inscrits dans le langage lui-même sexué, ils paraissent comme ayant toujours été là. Dès avant l'individu, dès avant le langage qui déjà les prévoit. La difficulté vient de ce que l'on ne peut identifier une caractéristique de sexe ou de genre déterminante et décisive, bienque les deux se prêtent à l'essentialisation. Ce différend, preçu comme fondamental - puisque condition de la vie - réussit à sexuer notre univers dans tous ses détails grâce à son statut très particulier, bien au delà de la différence naturelle. C'est bien pour cela qu'il est politique. Le différend des sexes reste encore une préoccupation de spécialistes ou de militants. Trés lentement, par les arguments de la critique féministe, il a fait son chemin dans les sciences humaines en commençant par l'anthropologie, aussi bien en tant que sujet d'étude qu'en tant que ce qui modifie la démarche. D'après Pierre Bourdieu, "la force particulière de la sociodicée masculine lui vient de ce qu'elle cumule et condense deux opérations: elle léaitime une relation de domination en l'inscrivant dans une nature biologique qui est elle-même une construction sociale naturalisée."23

On assimile le plus souvent le différend des sexes à la différence des sexes, celle-ci fantasmée, mais le premier est politique alors que la seconde, tout en étant supposée être naturelle, et aussi construite. Entre les deux termes il y a un rapport mouvant, instable, et une tension, une correspondance même, sans cependant qu'elle soit prédéterminée, définitive ou même identifiable. Le politique est finalement un pli de pouvoirpuissance potentiel. ${ }^{24}$ C'est le différend des sexes qui est philosophiquement intéressant car politique, et non la différence. Au contraire de ce que l'idée reçue de la différence des sexes peut faire entendre, le différend des sexes renvoie à la tension 
ката меѓу половите може да подразбира, спорот меѓу половите се повикува на една тензија на асиметричност или на онеправданост која постојано ја заматува, и ја надминува, дихотомијата која недоволно го искажува односот на неадекватност и однадвор и однатре. Ваквата асиметрија, тоа е самиот факт што не можеме никогаш да посочиме разлика која не останува нерешлива, и тоа нерешлива par excellence. Се работи за нешто што сее конфузија меѓ термините на дихотомијата, го пресекува нивниот однос и се поставува меѓу нив. Тоа значи дека спорот меѓу половите во себе носи безредие, во секој случај, постојана закана од ислревртување на хиерархијата која се крие во едноставната бинарна опозиција. Резултатот од тоа е амбивалентната смисла исто како и креативната сила на половата разлика. ${ }^{25}$ Овој имагинарен праг ја инкарнира разликата и ја претставува во исто време нерешливоста на релацијата: ниту пристрасност, ниту идеологија, ниту судбина, ниту предодреденост. Бидејќ, иако историјата го привилегирала машкиот субјект, играта секогаш одново започнува, секогаш непредвидлива. Всушност, ситуацијата на паланка ${ }^{26}$ може да се реши на многу различни начини чиј облик однапред не е утврден.

Разгледуваната разлика го освојува и наткодифик ува социјалното, политичкото, симболичното, имагинарното, таа е репер за секоја работа, иако се артикулира во различни режими на односите меѓу половите. Дури и електричните штекери се исто толку полово колку и мисловно определени. Таквата разлика симболично ги импрегнира со полови вредности сите разлики кои што постојат во сферата на она што претставува историски консензус. Исто така, таа го испресекува историското озаконување на хиерархиите кои се хранат со разлики. Не самата разлика меѓу половите, туку вредностите што културолошки й се припишуваат, ги сочинуваат свеста и потсвеста кои им претходат на секој социјален поредок.

Глобалниот патријархален консензус ${ }^{27}$ (првата од сите глобализации) кој се однесува на потчинетоста на сите жени во однос на сите мажи, се пројавува како мошне интересен, не само по она што тој претставува за истори- de l'asymétrie ou de l'injustice qui brouille constamment, et dépasse, la dichotomie insuffisante à exprimer ce rapport d'inadéquation du dehors et du dedans. Cette asymétrie, c'est même le fait que l'on ne puisse jamais mettre le doigt sur la différence qui ne peut que rester indécidable, l'indécidable par excellence. II s'agit là de quelque-chose qui sème la confusion entre les termes de la dichotomie et en traverse le rapport, s'entremet entre les deux. C'est dire que le différend des sexes porte en lui le bouleversement, en tout cas la menace constante de bouleversement de la hiérarchie déguisée en simple opposition binaire. Le résultat en est la signification ambivalente ainsi que la force créatrice de la différence des sexes. ${ }^{25}$ Ce seuil imaginaire incarne la différence et représente en même temps l'indécidable de la relation: aucun parti pris, aucune idéologie, aucun destin, aucune fatalité. Car bienque l'histoire ait privilégié le sujet masculin, le jeu est recommencé à chaque fois, jamais escompté. En effet, la situation de la palank $a^{26}$ peut être résolue de manières très différentes, la forme n'en est pas donnée d'avance.

La différence en question envahit et surcodifie le social, le politique, le symbolique, l'imaginaire, elle est un repère en toute chose, bienqu'elle s'articule en des régimes sexuels différents. Même les prises électriques sont pensées comme sexuées. Elle imprègne symboliquement par des valeurs sexuées toutes les autres différences dans la sphère de ce qui est historiquement consensuel. De méme, elle traverse la légitimation historique des hiérarchies qui se nourrissent des différences. Non pas la différence des sexes elle-même, mais les valeurs qu'on lui attribue culturellement, constituent le préalable conscient et inconscient de tout ordre social.

Le consensus patriarcal global ${ }^{27}$ (la première des globalisations) sur la soumission de toutes les femmes à tous les hommes est intéressant, au-delà de ce qu'il représente pour l'histoire des femmes, par ce qu'il sert universellement à rendre 
јата на жените, туку и по тоа што универзално служи да станат возможни и оправдани сите други потчинетости. Патријархатот не го разгледува посебно односот меѓу мажите и жените. Поскоро, тој е широко поле на кое се организира усогласување на различните типови доминација. Tоа се постигнува со помош на еден механизам на симболична „аналогија". Овој последниов потврдува еден претходен "договор меѓу половите" и кој de facto ги потчинува жените во однос на мажите. ${ }^{28}$ Патријархатот е одржуван и станува неопходен, однатре, како подршка на секој тип доминација по аналогија, и однадвор, како генерална рамка („неутрална" и неосознаена) на секоја социјална и етатистичка организација. Бивајќ и самиот еден вид хегемонија, тој е круцијален, неопходен и запишан во основата на секој друг тип на неегалитарна хегемонија. „Сексуалната контрола“ (онаа на односите меѓу половите како и на сексуалноста) е првата и најефикасна „лолициска“ власт. За да постои, таа нема потреба од државата, и й претходи бидејќи е присутна во секој вид заедница. Половиот поредок значи му претходи на етатистичкиот поредок во таа смисла што последниов ќе се потпира врз претходниот. ${ }^{29}$

Националната и светската економија, исто како и системот на држави, еволуираат преку помалку или повеќе препознатливи циклуси без да го допрат, освен можеби за да го реорганизираат, самиот патријархат. Можната и веројатна цикличност на односите меѓу половите иे бега на опсервацијата затоа што режимот на половите социјални односи е исклучително спор при големи размери и задржува еден заеднички именител на потчинетоста на жената на сите нивоа, што прави тој да изгледа непроменлив (иако тоа не е). Патријархалната хегемонија тогаш останува "нормалност" и е теоретизирана во различни дисциплини како несовладлива. Полот станува една нормативна категорија чија цел ја надминува сексуалноста. Ваквата инструментализација на една состојба на нештата која е веќе историска (доминацијата) преку нејзино претставување како трансисториска и природна, ја прави и самата инструментализација историска. Аналогијата што при тоа се извлекува за да се примени на други видови неправда, е всушност доделување есенција. Историјата на социјалните односи на половите е possibles et á justifier d'autres assujettissements. Le patriarcat ne concerne pas particulièrement la relation entre les hommes et les femmes. Plutôt, il est ce vaste champ où s'organise la concordance des différents types de domination. Cela se fait au moyen d'un mécanisme d'"analogie" symbolique. Celui-ci entérine un "contrat sexuel" préalable et qui assujettit de facto les femmes aux hommes. ${ }^{28}$ Le patriarcat est entretenu et rendu indispensable par l'intérieur en tant que soutien à tout type de domination par analogie, et par l'extérieur en tant qu'il est le cadre général ("neutre" et non perçu) de toute organisation sociale et étatique. Tout en étant lui-même une hégémonie, il est crucial, nécessaire, et inscrit à la base de tout autre type d'hégémonie inégalitaire. Le "contrôle sexuel" (celui du rapport entre les sexes, et aussi celui de la sexualité) est le premier et le plus efficace pouvoir "policier". Pour exister, il n'a pas besoin d'Etat, et lui précède, étant présent en tout type de communauté. L'ordre des sexes précède donc l'ordre étatique dans ce sens que ce dernier s'appuyera sur lui. ${ }^{29}$

L'économie nationale et mondiale, ainsi que le système des Etats évolue en cycles plus ou moins repérables sans toucher, sauf pour le réorganiser, au patriarcat. La cyclicité possible et probable du rapport des sexes, elle, échappe à l'observation car le régime des rapports sociaux de sexe est extrêmement lent à grande échelle et qu'il garde un dénominateur commun de subalternité des femmes à tous les niveaux qui le fait paraître inaltérable (ce qu'il n'est pas). L'hégémonie patriarcale reste alors la "normalité" et est théorisée en de différentes disciplines comme insurmontable. Le sexe devient une catégorie normative dont la cible dépasse la sexualité. Cette instrumentalisation d'un état de choses déjà historique (la domination) par sa présentation comme trans-historique et naturel, est elle-même historique. L'analogie qui en est déduite pour d'autres types d'injustice est une essentialisation. L'histoire des rapports sociaux des sexes est normalement masquée par la substitution du biologique au social et à l'historique. La différence biologique, supposée naturelle, est calquée sur l'inégalité sociale et récupérée pour faire paraître celle-ci comme 
секако маскирана преку замената на социјалното и историското со биолошкото. Биолошката разлика, претставена како природна, е пресликана врз социјалната нееднаквост и изведена за таа нееднаквост да изгледа исто така природна од своја страна. ${ }^{30}$ Но далеку од тоа да им биде наменет само на жените, доколку патријархатот сѐ уште се држи добро, тоа е затоа што останува основен инструмент во сите други типови подјарменост, суптилен влог во целата битка за хегемониска власт.

Забраната на инцестот, како и другите ограничувања на правата на телото и половоста кај оние кои се доминирани (жени; болни; деца; експлоатирани; колонизирани; воопшто, потчинетите луге) имаат за основна функција да ја гарантираат неегалитарната хиерархија и хегемонија. Така, пресликувањето на нееднаквоста меѓу половите врз едноставната и неутрална разлика меѓу половите е прв политички акт кој има за цел да им донесе власт на оние кои имаат најмногу слобода и полови права врз другите.

Прохибицијата на инцестот, со сите свои одлики на забрана, проследена е со редовни прекршувања од страна на татковците кои ги силуваат своите деца. Токму инцестот (од татко врз потомството) е постојано привикуван и забрануван, во исто време, поради фактот што пораката за неговата забрана е замаглена: бидејќи таа треба да ја легитимира најголемата полова слобода на таткото (кој го потврдува правилото како исклучок од таквата слобода) и му дава авторитет над другите. Доколку социјализацијата е барем малку попречена (едно премногу силно "его" или едно премногу слабо супер-его) таткото може забраната на инцестот да ја почуствува за себеси како неподнослива противречна стега. Контролата врз сексуалноста, на еден или на друг начин, е базичен инструмент на моќта и средство за репресија. Тој оддалеку ја надминува едноставната сексуалност, ја засегнува психо-физичката слобода, како на личноста, така и на нејзината група, и тоа од различни агли. Половоста се инструментализира за да се манипулира со заедницата, општеството, за да се организира државата. Цената се чини висока, бидејќи naturelle à son tour. ${ }^{30}$ Mais loin d'être destiné seulement aux femmes, si le patriarcat tient toujours bon, c'est qu'il est un instrument fondamental dans toutes les autres subjugations, un enjeu subtil dans la lutte pour le pouvoir hégémonique.

L'interdit de l'inceste, et d'autres limitations du droit à la sexualité et à leur corps de la part des dominés (femmes; malades; enfants; exploités; colonisés; hommes subalternes en général) ont pour fonction principale de garantir la hiérarchie et l'hégémonie inégalitaire. Ainsi, imprimer l'inégalité des sexes sur la simple et neutre différence des sexes est un premier acte politique et a pour but d'attribuer un pouvoir à ceux qui ont le plus de liberté et de droits sexuels sur les autres.

La prohibition de l'inceste, tout interdit qu'elle est, s'accompagne aussi par les transgressions régulières de certains pères qui violent leurs enfants. C'est que l'inceste (du père sur sa progéniture) est constamment invité et défendu en même temps, du fait que le message de son interdiction est brouillé: car cette dernière doit légitimer la plus grande liberté sexuelle du père (qui confirme la règle en tant qu'exception à cette liberté) et lui donner une autorité sur les autres. Si sa socialisation est un peu dérangée (un ego trop "fort", ou un super-ego trop faible), le pere peut trouver l'interdit de l'inceste être pour lui une contrainte contradictoire insupportable. Le contrôle de la sexualité, d'une manière ou d'une autre, est un instrument de base du pouvoir et un moyen de répression. II dépasse de loin la simple sexualité, il touche à la liberté psycho-physique aussi bien de la personne que de son groupe sous différents angles. On instrumentalise la sexualité pour manipuler la communauté, la société, pour organiser l'Etat. Le prix en paraît élevé, car il s'agit en général de réprimer la féminité et la "faiblesse" sexuelle imposée aussi bien à l'extérieur qu'en soi, d'où des contraintes également pour le groupe dominant. Mais ces "sacrifices" seront rémunérés 
главно се работи за тоа да се задуши женственоста и половата "слабост“ претставена однадвор, како и од внатре, од каде подеднакво се јавуваат ограничувања и за доминантната група. Но ваквите „жртви“ ке им бидат надоместени на најсилните преку престиж, власт, признавање на вредностите: она што членовите на групата го губат преку автоцензура на која се принудени, двојно им е вратено на генерички план, на планот на славата, на еден посакуван и дозволен континуитет. Накратко, она од што може да се создаде историја. Исто така, Клод Леви-Строс женската половост ја согледува како природна и асоцијална, а машката половост како организатор на социјалниот поредок: според него, оттаму произлегува потребата од брак (во корист на човекот и на човештвото), а оттаму и забраната на инцест со барање за хексогамија. Хексогамијата е со единствена смисла, и бидејќи светот се создава преку мажот, таа се сведува на размена на жени помеѓу клановите и помеѓу мажите. Ја предлагаме овде кратката критика на односните согледувања на ЛевиСтрос дадена од страна на Жарана Папиќ, онаа која зборува за „неговата претензија да дедуцира, почнувајки од еден културолошки специфичен духовен простор, особено дефиниран преку дзаконитее на метафизиката на присутноста, една добјективнае реконструкција на човековата природа дпо потеклое полова/родова, исто толку машка, колку и женска. Леви-Строс од ваквата природа изведе една универзална реконструкција на Првобитната човекова Сцена, онаа на преминот од природа во култура. Правејќи го ова, тој всушност изведе извесна (метафизичка) конструкција на половите/родовите десенцијалностите на човековата социјабилност - како спротиставени и дихотомни машки и женски природи и универзуми." ${ }^{\text {"31 }}$

Озаконувањето и оправдувањето на извесни социјални нееднаквости со други, подразбира исто така една хиерархија на тие нееднаквости. Секоја опозиција која имплицира хиерархиска перспектива (внатрешно/надворешно, тело/душа итн) содржи исто така исклучување на класата, расата (имагинарна), полот.Самата природа е инвоцирана како последен доказ во постапката на секуларизација на божествениот модел: не Бог, туку самата при- aux plus forts par le prestige, le pouvoir, la reconnaissance des valeurs: ce que les membres de ce groupe perdent par l'autocensure à laquelle ils sont obligés, leur est rendu redoublé sur le plan générique, en gloire, continuité admise et envie. Bref, de quoi construire une histoire. Ainsi, Claude Lévi-Strauss voit la sexualité féminine comme naturelle et associale, et la sexualité masculine comme organisatrice de l'ordre social: il en découle pour lui la nécessité du mariage (au profit de l'homme et donc aussi de l'humanité), et par là l'interdit de l'inceste avec l'exigence de l'exogamie. L'exogamie est à sens unique et, puisqu'il construit le monde par un biais masculin, elle se réduit à l'échange des femmes entre les clans et entre les hommes. Proposons ici la critique succinte de Lévi-Strauss à ce sujet par Zarana Papic, celle de "sa prétention à déduire, à partir d'un espace spirituel culturellement spécifique, particulièrement défini par les 'lois' de la métaphysique de la présence, une reconstruction 'objective' de la nature humaine 'originaire' sexuelle/de genre, aussi bien masculine que féminine. LéviStrauss a déduit depuis cette 'nature' une reconstruction universelle de la Scène humaine Originaire, celle du passage de la nature à la culture. Ce faisant il a en fait effectué une certaine construction (métaphysique) des 'essences' sexuelles/ de genre de la sociabilite humaine - en tant que natures et univers opposées et dichotomiques masculins et féminins." ${ }^{11}$

La légitimation et la justification de certaines inégalités sociales par d'autres comprend elle-même une hiérarchie de ces inégalités. Toute opposition impliquant une perspective hiérarchique (intérieur/extérieur, corps/âme etc) contient aussi bien l'exclusion de classe, de race (imaginaire), de sexe. La nature, elle, est invoquée comme preuve ultime dans un tour de sécularisation du modèle divin: ce n'est pas dieu, mais ellemême, la nature, qui veut la domination. Ainsi, dans la séparation 
рода ја посакува доминацијата. Така, во одвојувањето на душата од телото, душата може да го претставува покорениот, благодарение на едно лукавство со кое филозофот си ги обезбедува двата краја на равенката: душата е всушност тело на жената. ${ }^{32}$

Како било можно импрегнирањето на половите нееднаквости со другите хиерхии, и зошто половиот критериум поскоро од кој било друг е земен за базичен модел?

Нормативниот пол, т.е. половите улоги, правото на половост или не, се значително селективни и хиерархиски расположени, припаѓајќи на доменот на власта. Токму преку ваквото ефикасно влијание, еден режим на полови односи на најелементарно ниво (во семејството, обичаите, социјалната практика итн.) може да формира и услови создавање на една посредна формација, онаа од јавен ред или едноставно политички систем. Со забранување или лимитирање на половоста може да се угнетуваат, казнуваат, скротуваат, уценуваат, инструментализираат и манипулираат не само индивидуите туку и колективите. Насилството е пред сѐ сегрегација на половите или насилството ја започнува сегрегацијата која ќе послужи како симболична аналогија за другите нејзини форми. Културите кои што знаеле да негуваат меки и еластични форми на полови идентитети (што воопшто не е случај со Западот, освен од неодамна), како и помалку хиерархиски поставени односи меѓ половите, се токму оние кои развиле и одржале извесен отпор кон насилството. Во таа смисла, позната е врската меѓу колонијалната конструкција и употребата на половоста зо таа цел, односно егзалтацијата на хипер-мажественоста. ${ }^{33}$ Колонијализмот само дополнително ја зацврсти традиционалната мачо-суровост преку понижување на мажественоста на колонизираните, кои себеси се доживуваат споредувани, о каков ли срам, со жените, и принудувани уште посилно да применуваат насилство спрема жената (и спрема потчинетите касти-класи) за да му се спротистават на колонизаторот кој ги согледува како феминизирани итн. Едно наддавање на половата симболика се воспоставува меѓу нив, во исто време додека кастите, за кои што веруваме дека се непромен- de l'âme et du corps, l'âme peut représenter le réprimé grâce à une supercherie par laquelle le philosophe s'approprie les deux bouts de l'équation: l'âme est en effet un corps de femme. ${ }^{32}$

Comment le télescopage de l'inégalité des sexes sur les autres hiérarchies sociales a-t-il été possible, et pourquoi le critère du sexe plutôt qu'un autre pour modèle de base?

Le sexe normatif, c'est à dire les rôles sexuels, le droit à la sexualité ou non, sont hautement sélectifs et hiérarchisants, relevant du domaine du pouvoir. C'est ainsi que, par cette emprise efficace, un régime des rapports de sexe au niveau le plus élémentaire (qans la famille, dans les coutumes, dans la pratique sociale etc.) peut informer et conditionner une formation intermédiaire, celle de l'ordre public ou simplement le système politique. En interdisant la sexualité ou en la limitant, on peut opprimer, punir, maîtriser, faire chanter, instrumentaliser, manipuler non seulement des individus, mais des collectivités. La violence est avant tout ségrégation des sexes, ou elle commence par celle-ci qui va servir d'analogie symbolique pour ses autres formes. Les cultures qui ont su cultiver des formes souples et fluides d'identités sexuelles (ce n'est pas du tout le cas en Occident sauf plus récemment), ainsi que des rapports moins hiérarchisants entre les sexes, sont également celles qui ont développé et maintenu une certaine résistance à la violence. Dans ce sens, le lien entre la construction coloniale et l'utilisation à cet effet de la sexualité, l'exaltation de l'hyper-virilité, sont connus. ${ }^{33}$ Le colonialisme a donné un tour de vis supplémentaire au machisme traditionnel de la cruauté, par l'humiliation de la virilité des coloniaux, qui se voient comparés, ô déshonneur, aux femmes, et obligés de recourir plus encore à la violence contre les femmes (et contre les castes-classes soumises) pour faire face au colonisateur qui les voit comme efféminés etc. Une surenchère de la sexualité symbolique se met en place entre les deux, en même temps que les castes, que l'on voudrait croire immuables, s'adaptent très bien à la reconfiguration hégémonique. Mais dans la construction de la colonie, qui se fait aussi bien par les uns que par les autres, l'oppression des femmes redoublée fera bon ménage avec les tentatives de 
ливи, многу добро се адаптираат на реконфигурираната хегемонија. Но во конструкцијата на колонијата, во која подеднакво учествуваат и едните и другите, удвоеното угнетување на жените добро се спојува со обидите за помирување преку модернизација, интеграција и прифаќање на мешањето на расите иако тоа не значи и еднаквост. Денеска, додека се води една бесконечна дебата околу резервираните места (квоти) за жените, забележуваме дека доминантните елити се интересираат за нив во онаа мера во која тоа може да им помогне да се спротистават на барањата на дефаворизираните касти, додека овие се спротиставуваат на претставувањето на жените освен ако немаат сопствена полза. Помеѓу доминантните мажи и доминираните мажи, премолчен договор е секогаш можен по повод една иста тема - „природната“ угнетеност на жените. Ваквиот компромис, признаен или не, е често пати потребен и претходи на секој друг односен договор. Така, уште еднаш, жените во сопственото тело сврзуваат конструкции на социјално и политичко експериментирање. ${ }^{34}$

Односот меѓу половите е етаблиран во нормативна категорија, дефиниран по обичај и инерција, и како таков, ниту е неопходно експлицитно искажан со политички термини, ниту е нужно испишан во законот, односно невидлив со силата на самата негова евидентност, универзално и хегемониски "консензуален", тој директно влегува во десьиницијата на секој друг идентитет. Националниот идентитет е најпрвиот идентитет и оној кој најмногу се потпира врз еден "социјален договор" кој се подразбира, повикувајќи се на него сѐ до самиот јазик. Секое конституирање на нацијата започнува, значи, со една редефиниција на односите меѓу половите и дескрипција на очекуваната улога на секој од нив во раскажувањето кое тече само од себе.

*Овој налис е извадок од воведот во Nation et différences des sexes, ракопис од книга која е во процедура на редактирање. réconciliation par la modernisation, d'intégration et d'acceptation d'un métissage même si celui-ci n'est pas à égalité. Aujourd'hui, alors qu'un débat interminable a lieu autour des reservations (quotas) pour les femmes, on s'aperçoit que les élites dominantes s'intéressent à elles seulement dans la mesure où cela peut les aider à résister aux revendications des castes défavorisées, alors que celles-ci s'opposent à la représentation des femmes sauf quand ça les arrange à leur tour. ${ }^{34}$ Entre les hommes dominants et les hommes dominés, un accord tacite est toujours possible à propos d'un seul sujet - l'oppression "naturelle" des femmes. Ce compromis, avoué ou non, est souvent nécessaire et est le préalable de tout autre accord sur les termes. Ainsi, une fois de plus, les femmes soudent, dans leur corps, les constructions de l'expérimentation sociale et politique. ${ }^{35}$

Le rapport des sexes est établi en catégorie normative, défini par la coutûme et l'inertie, et en tant que tel, ni nécessairement énoncé explicitement en termes politiques ni forcément inscrit dans la loi, ou invisible par la force même de son évidence, universellement et hégémoniquement "consensuel", il rentre directement dans la définition de toute autre identité. La première et celle qui le plus s'appuie sur ce "contrat social" sous-entendu, est l'identité nationale, qui en reprend jusque le langage. Toute constitution de la nation commence donc par une redéfinition des rapports de sexe et la description du rôle attendu de chacun d'entre eux dans le récit que l'on se fait de soi.

* Cet article est un extraît de l'introduction à Nation et différence des sexes, manuscrit de livre en cours de rédaction.

Превод: Елисавета Поповска 


\section{БЕЛЕШКИ}

1 Philippe Descola, "Où s'arrête la nature? Oú commence la culture?", Le Monde, 31 март 2001, стр. 16. Во таа смисла, една нова антропологија би била во суштина една "антропологија на природата".

2 Robert W. Connel, "Understanding Change in Gender", прилог кон симпозиумот "Women and Radical Change", Institute for International Studies, University of Technology, Sydney, Bowral, 2-3 април 2001. Според овој автор, социјалните односи на половите би можеле еден ден категоријата на "родот" да ја направат безопасна и исцрпена во смисла на дискриминација "преку внатрешно расцепување така што односите во еден домен на практика престануваат да ги зајакнуваат оние во друг домен на практика".

3 M. Foucault, La volonté de savoir, Histoire de la sexualité, 1 , Gallimard 1994, стр. 207

- Ritu Menon, "Do Women Have a Country? The Question of Citizenship in Post-Partition India", in Rada Ivekovic \& Julie Mostov, Nation and Gender, Longo Editore, Ravena, во печат. Исто така: Ritu Menon, "Cartographies of Nations and Identities. A Post- Partition Predicament" in Interventions. International Journal of Postcolonial Stud. ies, Vol.1, no.2,1999, специјален број посветен на поделбата на Индија уредуван од самата Риту Менон. Од истиот автор, "La dynamique de la division", in Transeuropéennes, n. 19/20, 2001.

5 Nadje Al-Ali, "Review Article. Nationalisms, national identities and nation states: gendered perspectives", in: Nations and Nationalism, vol.6. Part 4, October 2000, special issue on "Gender and $\mathrm{Na}$ tionalism", ed. by Deniz Kandiyoti, стр. 639.

- Etienne Balibar вo E. Balibar \& I.Wallerstein, Race, Nation, Classe.Les identités ambiguës, La Découverte, Paris, 1988, стр. 136 и на други места.

7 Изборите од 13 мај 2001 го донесуваат на власт во Италија Силвио Берлускони, десничарски популист, кој изјавува дека поскоро би сакал да ја организира државата по углед на едно претпријатие. Замислата за Држава-нација овде уште повеќе се оддалечува од "женските" (патријахални) вредности, за да најави една предоминација на машкиот модел и една значителна "маскулинизација" на жените во онаа мера во која тие успеваат да напредуваат низ модернитетот и нивната јавна видливост.

- Sylvia Walby, "Gender, Nations and States in a Global Era", in Nations and Nationalisms, vol.6, Part 4, October 2001, special issue on "Gender and Nationalism", ed. by Denize Kandiyoti, стр.523-540. Концептот го адаптирам за сопствени потреби, применувајќи го на различни нивоа на социјалната скала.

\section{NOTES}

1 Philippe Descola, "Où s'arrête la nature? Où commence la culture?", Le Monde, 31 mars 2001, p. 16. Dans ce sens, une nouvelle anthropologie serait en vérité une "anthropologie de la nature".

${ }^{2}$ Robert W. Connell, "Understanding Change in Gender", communication au colloque "Women and Radical Change", Institute for International Studies", University of Technology, Sydney, Bowral, 2-3 April 2001. Selon cet auteur, les rapport sociaux des sexes pourraient un jour rendre la catégorie de "genre" inoffensive et caduque en termes de discrimination "par une dissociation intérieure de sorte que les rapports dans un domaine de pratique cessent de renforcer ceux d'un autre."

${ }^{3}$ M. Foucault, La volonté de savoir, Histoire de la sexualité, 1 , Gallimard 1994, p, 207.

${ }^{4}$ Ritu Menon, "Do Women Have a Country? The Question of Citizenship in Post-Partition India", in, Rada Ivekovic \& Julie Mostov, Nation and Gender, Longo Editore, Ravenne, sous presse. Egalement: Ritu Menon, "Cartographies of Nations and Identities. A Post-Partition Predicament" in Interventions. International Journal of Postcolonial Studies, Vol. 1, no. 2, 1999, numéro spécial sur la Partition de l'Inde dirigé par Ritu Menon elle-même. Du même auteur, "La dynamique de la division", in Transeuropéennes, n. 19/20, 2001.

${ }^{5}$ Nadje Al-Ali, "Review Article. Nationalisms, national identities and nation states: gendered perspectives", in: Nations and Nationalism, vol. 6, Part 4, October 2000, special issue on "Gender and Nationalism", ed. by Deniz Kandiyoti, p. 638.

${ }^{6}$ Etienne Balibar dans E. Balibar \& I. Wallerstein, Race, Nation, Classe. Les identités ambiguës, La Découverte, Paris 1988, p. 136 et ailleurs.

7 Les èlections du 13 mai 2001 amènent au pouvoir en Italie Silvio Berlusconi, populiste de droite, qui déclare plutôt vouloir organiser l'Etat à l'image de l'entreprise. L'imaginaire de l'Etat-nation s'éloigne ici encore plus des valeurs (patriarcales) "féminines", pour annoncer une prévalence du modèle masculin et une "masculinisation" majeure des femmes dans la mesure où elles réussissent et avancent dans la modernité et dans leur visibilité publique.

"Sylvia Walby, "Gender, nations and states in a global era", in Nations and Nationalism, vol. 6, Part 4, October 2000, special issue on "Gender and Nationalism", ed. by Deniz Kandiyoti, pp.523-540. J'adapte pour mes besoins le concept, en l'appliquant à différents niveaux de l'échelle sociale. 
- Roter Stern, Frankfurt a.M./Basel 1977, 1978 (3e edition). Цитирано според српскохрватскиот превод, Muške fantazije, 1-4, GZH, Zagreb, 1983, t.3,cтp.59 ff.

10 Kumkum Sangari \& SudeshVaud (eds.), Recasting Women: Essays in Indian Colonial History, Rutgers University Press, New Brunswick, New Jersey 1990, стр.5, и понатаму.

11 "Une dernière envolée qui dure" in Transeuropéennes, $\mathrm{n}$. 19/20, 2001, и целиот специјален број кој се однесува на поделбите.

12 патриотизмот како секуларизирана форма од љубовта кон Бога.

${ }^{13}$ Georges Duby, Måle moyen âge. De l'amour et autres essais, Flammarion, Paris, 1988: "Que sait-on de l'amour en France au XIle siècle?", стр. 34 и понатаму.

26 Ashis Nandy, The Intimate Ennemy. Loss and Recovery of Self under Colonialism, OUP, Delhi, 1983.

15 Иван Чоловиќ, Бордел ратника, XX vek, Beograd 1993, cтp. 73.

16 После религијата, секуларизираната филозофија е таа која што всушност настојува систематски да ја рефундира и пренесува патријахалната нормативност на поредокот. Valeria Valcárcel, La politica de las mujeres, Ediciones Cátedra, València, p. 74.

17 Документ циклостил "Fundacòn para la democracia Manuel Colòm Argueta. Proyecto: Liderazgo y cuestiones étnico cultural y de género", Taller para el personal administrativo, docente yestudiantil, Guatemala 9-4-1999, стр.2.

1в Има мноштво можни дефиниции на нацијата, но, за несреќ, сите без соодветен заклучок, кои како основачки принцип можат да се повикаат на религијата (дефиниција која е главно недоволна), јазикот, културата, потеклото, економијата, заедничките проекти, па дури и на војната како "работа" итн.

19 Françoise Collin, Le différend des sexes, Eds. Pleins feux, Nantes, 1999.

20 F. Collin, Evelyne Pisier, Eleni, Varikas, Les femmes de Platon à Derrida.Anthologie critique. Paris, Plon, 2000.

21 Но неусогласеноста на нивните барања (на работниците) во однос на придобивките на средната класа не дозволуваше ваквото исчекување да се разбере преку термините на политиката", Michéle Riot- Sarcey, Le Réel de l'utopie. Essai sur la politique au XXe siècle. Albin Michel, Paris, 1998, стр. 219

22 Jacques Rancière, La Mésentente. Politique et Philosophie, Galilié, Paris, 1998, стр. 29.

${ }^{23}$ Pierre Bourdieu, La domination masculine, Seuil, Paris,1998, стр.29.

24 Под "потенцијален" подразбирам дека може во исто време да биде реализиран или не.
${ }^{9}$ Roter Stern, Frankfurt a.M./Basel 1977, 1978 (3e edition). Cité d'après la traduction serbocroate, Muške fantazije, 1-4, GZH, Zagreb 1983; t.3, p. $59 \mathrm{ff}$.

${ }^{10}$ Kumkum Sangari \& Sudesh Vaud (eds.), Recasting Women: Essays in Indian Colonial History, Rutgers University Press, New Brunswick, New Jersey 1990, p. 5, ff.

1 "Une dernière envolée qui dure", in Transeuropéennes, $\mathrm{n}$. $19 / 20,2001$, et tout le numéro spécial sur les partitions.

12 le patriotisme, en tant que forme sécularisè de l'amour de dieu.

${ }^{13}$ Georges Duby, Mâle moyen âge. De l'amour et autres essai, Flammarion, Paris 1988: "Que sait-on de l'amour en France au XIle siècle?", p. $34 \mathrm{ff}$.

${ }^{14}$ Ashis Nandy, The Intimate Ennemy. Loss and Recovery of Self under Colonialism, OUP, Delhi 1983.

15 Ivan Colovic, Bordel ratnika, XX vek, Beograd 1993, p. 73.

${ }^{16}$ Après la religion, c'est bien la philosophie sécularisée, d'ailleurs, qui prend soin de refonder systématiquement et de véhiculer la normativité patriarcale de l'ordre. Valeria Valcárcel, La política de las mujeres, Ediciones Cátedra, València 1997, p. 74.

${ }^{17}$ Document cyclostylé "Fundación para la democracia Manuel Colóm Argueta. Proyecto: Liderazgo y cuestiones étnico cultural y de género", Taller para el personal administrativo, docente y estudiantil, Guatemala 9-4-1999, p. 2.

${ }^{18}$ II y a des quantités de définitions possibles, hélas toutes inconclusives, de la nation, qui peut invoquer la religion (définition en général insuffisante), la langue, la culture, l'origine, l'économie, le projet commun, et même la guerre en tant que "travail", etc. comme principe fondateur.

${ }^{19}$ Françoise Collin, Le différend des sexes, Eds. Pleins feux, Nantes 1999.

${ }^{20} \mathrm{~F}$. Collin, Evelyne Pisier, Eleni Varikas, Les femmes de Platon à Derrida. Anthologie critique, Paris, Plon 2000.

21 "Mais le décalage de leurs revendications [des ouvriers] par rapport aux acquis de la classe moyenne ne permettait pas de comprendre cette attente en termes politiques." Michèle Riot-Sarcey, Le Réel de l'utopie. Essai sur le politique au XIXe siècle, Albin Michel, Paris 1998, p. 219.

22 Jacques Rancière, La Mésentente. Politique et Philosophie, Galilée, Paris 1995

${ }^{23}$ Pierre Bourdieu, La Domination mascuine, Seuil, Paris 1998, p. 29. pas l'être.
${ }^{24}$ Par "potentiel", j'entends qu'il peut ả la fois être rẻalisé ou ne 
25 Homi Bhabha, The location of Culture, Routledge, London New York 1994, v.p.128

26 Паланка е централен термин употребен од страна на Радомир Константиновиќ, Filozofija palanke, Nolit, Beograd 1981. Литерарно земено, овој термин означува наедно "паланка" и "периферија": па сепак, авторот не го употребува во топографска смисла, туку во смисла на состојба на духот, или поскоро на привидението. Тој означува помалку или повеќе една некомплетна интеграција, едно општество на ниво на заедница и во дел се уште рурално, значи во транзиција,чии што спротивности, во соочувањето со модернитетот, можат да доведат - но не и нужно - до сите видови на насилство. Тоа е еден секогаш можен тоталитаризам, состојба на еден латентен фашизам. Овој тип на општество не е специфичен за социјализмот, туку за почетокот на модернизмот, и тоа модернизам со лош почеток. Некои концепти на Р. Константиновиќ ги преземав во мојата книга Autopsia dei Balcani. Saggio di psico-politica, Raffaello Cortina Editore, Milan 1999.

27 "патријахалното", далеку од тоа да биде маскулинизирано онтолошки и биолошки, овде е само факт дека машкото историски преовладало како симболичен систем и однос на сили. Тоа се однесува на сѐ, и ги исклучува оние мажи и жени на кои им припишува природност или им оневозможува пристап до разумот. Тој е првобитна конфигурација на секоја хиерархија.

${ }^{28}$ Colette Guillaumin, Sexe, Race et Pratique du pouvoir. L'idée de Nature. Cóté-femmes, Paris 1992.

29 Partha Chaterjee, "More on Modes of Power and the Peasantry", in A. Guha, G. Chakravorty Spivak (eds.), Selected Subaltern Essays, OUP, Nem York - Oxford 1988, p.363.

so Стриктно почитувана во овој текст, дотолку повеќе што таа не е многу прифатена во францускиот јазик. Концепту алната рамка во францускиот јазик е поразлична од онаа која е во употреба во англискиот јазик. Оваа дистинкција вреди исто колку и антропопошката структуралистичка дистинкција помеѓ "природа" и "култура", која е исто така практична, но теориски е двосмислена и конечно неодржлива, бидејќ во една крајна анализа доведува до есенцијализација на категориите. Како и секоја постапка или концептуализација во корист на дефаворизираните, и оваа дистинкција е со две острици: концептот на род (gender) ја има предноста да покаже дека не е легитимно да се правда симболичната и социјалната исклучивост на жените преку аналогија со биологијата. Но ја има слабоста да доведе до претпоставка дека постои една "биолошка природа" на жената (а впрочем и на мажот), која е добро дефинирана и вонисториска, а тоа е полот (sex), оставена настрана од социјалните науки и филозофијата.
25 Homi Bhabha, The Location of Culture, Routledge, London New York 1994, v. p. 128.

${ }_{26}$ Palanka est le terme central utilisé par Radomir Konstantinovic, Filozofija palanke (La philosophie de bourg), Nolit, Beograd 1981. II veut dire littéralement à la fois "bourg" et "périphérie"; cependant, l'auteur ne l'utilise pas dans un sens topographique, mais dans le sens d'un état d'esprit, ou plutôt d'un spectre. II désigne plus ou moins une intégration incomplète, une société encore communautaire et en partie rurale, en transition donc, dont les contradictions, dans l'affrontement de la modernité, peuvent porter - mais non nécessairement - à toutes sortes de violence. C'est le totalitarisme toujours possible, un état de fascisme latent. Ce type de société n'est pas spécifique du socialisme, mais d'un début de modernité ou d'une modernité mal partie. J'ai repris certains concepts de R. Konstantinovic dans mon livre Autopsia dei Balcani Saggio di psico-politica, Raffaello Cortina Editore, Milan 1999.

27 "patriarcal", loin d'ètre masculin ontologiquement ou biologiquement, n'est ici que le fait que le masculin a historiquement prévalu en tant que système symbolique et rapport de forces. II concerne tous, et exclut ceux et celles à qui il attribue la nature ou nie l'accès à la raison. Il est la configuration première de toute hiérarchie.

${ }^{28}$ Colette Guillaumin, Sexe, Race et Pratique du pouvoir. L'idée de Nature, Côté-femmes, Paris 1992.

${ }^{29}$ Partha Chatterjee, "More on Modes of Power and the Peasantry", in R. Guha, G. Chakravorty Spivak (eds.), Selected Subaltern Essays, OUP, New York - Oxford 1988, p. 363.

${ }^{30}$ La distincion anglosaxone entre sex et gender est theoriquement insoutenable bienque politiquement souvent utile. Elle l'a surtout été au début des deux vagues de luttes féministes du 20 e siècle. Elle ne sera pas maintenue strictement dans ce texte, d'autant plus qu'elle est mal acceptée en français. Le cadre conceptuel de ce dernier est diffèrent de celui en vigueur dans la langue anglaise. Cette distinction ne vaut pas mieux que la distinction anthropologique structuraliste entre "nature" et "culture", elle même pratique, mais théoriquement ambiguë et finalement non viable, car elle mène en dernière analyse à l'essentialisation des catégories. Comme toute démarche ou conceptualisation en faveur des défavorisés, cette distinction est à double tranchant: le concept de gender a l'avantage de montrer qu'il n'est pas légitime de justifier l'exclusion symbolique et sociale des femmes par analogie avec la biologie. Mais il a le désavantage de faire supposer qu'il y aurait une "nature biologique" de la femme (et d'ailleurs, de l'homme) bien définie et anhistorique, sex, laissée pour compte par les sciences sociales et la philosophie. 
${ }_{31}$ Zarana Papic, Polnost i kultura, XX vek, Belgrade, 1997, cтp.333.

32 Giulia Sissa, L'Ame est un corps de femmes, Ed. Odile Jacob, Paris 2000.

33 Kumkum Sangari, Sudesh Vaid (eds.), Recasting Women. Essays in Indian Colonial History. Rutgers Univerity Press, New Brunswick (New Jersey) 1989; Klaus Theweleit, Mânnerphantasien, op. cit;; Ashis Nandy, The Intimate Enemy, op. cit;; Mario Roberto Morales, La articulcòn de las diferencias, o El sindrom de Maximòn. Los discursos literarios y politicos del debate interétnico en Guatemala, Flasco, Guatemala 1998.

34 Nivedita Menon, "Elusive 'Woman': Feminism and the Woman's Reservation Bill", in Economic and Political Weekly, vol. XXXV, n. $43 \& 44,21-28$ octobre 2000, pp. 3835-3844; Zoya Hasan,"Women's Reserved Seats and the 'Politics of Presence'. 'The Curious Case of 500 Versus 42"', manuscrit (2000), à paraître dans: Constitutional Theory and Political Practice: Fifty Years of the Republic, ed. by Zoya Hasan, E. Sridharan and S. Sudershan.

35 Спогодбите меѓу последователните елити во врска со положбата на жените се дел од договорот при примопредавањето на власта. Така, револуцијата на Хомеини која ветуваше еднаквост за време на немирниот период на борбата, по неговото доагање на власт воведе шарија (charia) за сето она што се однесува на жените (сепак тие успеаја да го сменат нејзиниот правец со тоа што изнудија укинување на правото на протерувањето на жената). Во Алжир, иако францускиот граѓански кодекс остана на сила и по ослободувањето, исламистите од 1973 г. им препуштија на судиите право на избор да го почитуваат или не, пред да биде воведен во 1980 г. Законот за семејни односи кој го регулира личниот статус на жената и ја ограничува нејзината слобода. Во 1979, во Египет, најпрвин претседателот Садат преку декрет донесува закон кој го подобрува легалниот статус на жената, а потоа отстапува пред исламистите и прогласува шарија во 1980. Во Индија, законодавството ги презема од Англичаните граганските закони одвоени од религијата, со што секое прашање во врска со правдата за жените е препуштено на самата религиозна заедница и на обичајното право, интерпретирајки ги на тој начин различно граѓанскиот статус на жената, определен од припадноста кон религијата и заедницата, и граганскиот статус на мажот, кој е од лаичка и унитарна природа. Во етнократиите кои произлегоа од Југославија, правото на жените да располагаат со своето тело (контрола на раѓањата итн) како и некои други права, веднаш беа подложени на ревизија без тоа да предизвика особена реакција од страна на старите елити или на анти-националистичките интелектуалци (мажи). Со доаѓањето на Џ. В. Буш на власт, исто така, токму во САД извесни придобивки на жените беа ставени под прашање.
${ }^{31}$ Z. Papic, Polnost $i$ kultura, XX vek, Belgrade 1997, p. 333. Paris 2000 .

${ }^{32}$ Giulia Sissa, L'Ame est un corps de femme, Ed. Odile Jacob.

${ }^{33}$ Kumkum Sangari, Sudesh Vaid (eds.), Recasting Women. Essays in Indian Colonial History, Rutgers University Press, New Brunswick (New Jersey) 1989; Klaus Theweleit, Mănnerphantasien, op.cit; Ashis Nandy, The Intimate Enemy, op.cit.; Mario Roberto Morales, La articulacón de las diferencias, o El sindrome de Maximón. Los discursos literarios y políticos del debate interétnico en Guatemala, Flasco, Guatemala 1998.

${ }^{34}$ Nivedita Menon, "Elusive 'Woman': Feminism and the Woman's Reservation Bill", in Economic and Political Weekly, vol. XXXV, n. 43 \& 44, 21-28 octobre 2000, pp. 3835-3844; Zoya Hasan,"Women's Reserved Seats and the 'Politics of Presence'. 'The Curious Case of 500 Versus 42'", manuscrit (2000), à paraître dans: Constitutional Theory and Political Practice: Fifty Years of the Republic, ed. by Zoya Hasan, E. Sridharan and S. Sudershan.

${ }^{35}$ Les transactions des élites successives au sujet des femmes font partie du tableau dans les périodes de passation de pouvoir. Ainsi, la révolution de Khomeini, qui promettait l'égalité durant la période trouble de la lutte, a introduit la charia pour tout ce qui concerne les femmes dès son arrivée au pouvoir (celles-ci ont d'ailleurs réussi à renverser la vapeur plus tard en faisant abolir la répudiation). En Algérie, bien que le Code civil français soit resté en vigueur à la libération, les islamistes ont laissé le choix aux juges dès 1973 de ne pas le suivre, avant que le Code de la famille qui règle le statut personnel de la femme et limite sa liberté ne soit introduit en 1984. En 1979, en Egypte, le président Sadat fait d'abord passer par décret une loi qui améliore le statut légal des femmes, puis cède aux islamistes et fait proclamer la charia en 1980. En Inde, la législation reprend des Anglais les codes civils séparés par religion, ce qui relègue toute question de justice concernant les femmes à la seule communauté religieuse et au droit coutumier, interprétant ainsi différemment la citoyenneté des femmes, soumise à l'appartenance religieuse et communautaire, et celle des hommes, laïque et unitaire. Dans les ethnocraties issues de la Yougoslavie, le droit des femmes de disposer de leur corps (contrôle des naissances etc.) et certains autres droits furent immédiatement remis en cause sans susciter de réaction particulière de la part des anciennes élites ou des intellectuels (hommes) anti-nationalistes. A l'arrivée de G. W. Bush au pouvoir, d'ailleurs, c'est aux Etats Unis que certains acquis des femmes furent remis en question. 